\title{
Diagnosing Shocks in Stock Market Returns of Greater China*
}

\author{
W.C. Lo \\ Open University of Hong Kong, Hong Kong \\ W.S. Chan \\ The University of Hong Kong, Hong Kong
}

\begin{abstract}
Using a modified outlier identification procedure by Chen and Liu (1993), this article studies the large shocks of the Greater China stock markets. We find that while large shocks are typical in all the markets and more outliers appear in the Chinese stock markets than in the other markets. We also find that most of the outliers identified in the Hong Kong market cluster in the periods of the 1997 Asian financial crisis and after the government's market intervention in August 1998. With the exception of Hong Kong, most outliers seem to be driven by local events (JEL C52, G14, G15).
\end{abstract}

Keywords: Greater China stock markets, large shocks, time series outliers.

\section{Introduction}

The emergence of the Greater China economic bloc triggered by the economic reform in China since the early eighties has been a subject of increasing interest in recent years (see, for example, Ash and Kueh, 1993; Jones et al. 1993; Naughten, 1997; Sung, 1992, among others). The three Greater China economies, namely, the ethnically homogeneous China, Hong Kong and Taiwan, complement one another, with China providing land and labor for manufacturing at low costs, and Taiwan and Hong Kong providing capital and technical expertise.

*We are grateful to Professor Yin-Wong Cheung and the referees, whose helpful comments have led to this more succinct version of our work. The first author is grateful to the Open University of Hong Kong for their generous financial support.

(Multinational Finance Journal, 2000, vol.4, no. 3\&4, pp. 269-288)

(CMultinational Finance Society, a nonprofit corporation. All rights reserved.

DOI: $10.17578 / 4-3 / 4-7$ 
An important component of economic reforms in China is her financial liberalization. Since the early 1990s, China has initiated a series of policies for financial liberalization. To enhance the capacity to raise capital, the State Council Securities Commission of China allowed her two stock exchanges, Shanghai Stock Exchange (SHSE) and Shenzhen Stock Exchange (SZSE), to issue B-shares for foreign investors, in addition to the A-shares which only domestic investors are allowed to buy. In addition, selected companies in China are allowed to list, referred to as the $\mathrm{H}$ shares, in the Stock Exchange of Hong Kong (SEHK). There are also Hong Kong registered companies that have powerful links with state-owned companies in Mainland China. These companies, referred to as Red Chips, are the arms of their mainland parents to raise capital. Hong Kong, being the most developed and least regulated capital market in the Greater China region, has become an important channel for China's enterprises to raise capital.

Empirical studies indicate that emerging stock markets tend to become larger, more liquid, more volatile, and more integrated after financial market liberalization (Levine and Zervos, 1998; Ragunathan, 1999). There are increasing numbers of studies to investigate the performance of the Greater China stock markets in recent years (Song et al., 1998; Su, 1999; Su and Fleisher, 1999; Xu and Wang, 1999; Chou, et al., 1999; and Lee et al., 1999). These studies focus on the returns and volatility of the emerging markets, investors behaviour, and the linkages to the mature markets such as the United States'. Moreover, some evidence indicates that the stock markets in the Greater China economies are integrated, with Hong Kong as the leading market in stock returns (Chan et al., 1999).

This paper addresses the Greater China stock market integration by analyzing the large shocks of the stock markets. This is important because large shocks are likely to be typical in macroeconomic time series (Blake and Fomby, 1994). Since investors looking for crossborder investment opportunities consider the risk diversification as well as the rate of return, it is important to understand reaction of these economies to important events such as the political turmoil and financial crisis. The remaining part of this paper is organized as follows. Section II gives a description of the time series outlier models. Section III contains the data description and empirical results. The last section concludes. 


\section{Methodology}

Shocks in a time series can be quantified by outlier models. In this section we review the time series outlier detection approach due to Chen and Liu (1993). We shall restrict the discussion to points necessary for describing the applications in this paper. Further details can be found in Tsay (1988), Chen and Liu (1993) and Balke and Fomby (1994).

Suppose that an outlier-free time series $X_{t}$ has the stationary ARMA $(p, q)$ representation:

$$
\phi(L) X_{t}=\theta(L) e_{t}
$$

where $L$ is the lag operator such that $L^{s} X_{t}=X_{t-s}$,

$$
\begin{aligned}
& \phi(L)=1-\phi_{1} L-\cdots-\phi_{p} L^{p}, \\
& \theta(L)=1-\theta_{1} L-\cdots-\theta_{q} L^{q},
\end{aligned}
$$

and $e_{t}$ is i.i.d. $N\left(0, \sigma^{2}\right)$.

Time series are often susceptible to external shocks such as famine, war, changes in government policies and so on. The consequences of these interruptive shocks create aberrant observations, which are usually referred to as outliers. Most outliers are not simply spurious observations (e.g., recording or typing errors). They may contain important information about the external shocks affecting the series. In general, outliers in time series can be viewed as the result of nonrepetitive interventions. Thus, a contaminated time series $Y_{t}$ consists of an outlier-free time series $X_{t}$ plus an exogenous intervention effect $\Delta_{t}(t, \omega)$, i.e.,

$$
Y_{t}=X_{t}+\Delta_{t}(T, \omega)
$$

where $T$ is the location of the outlier and $\omega$ is the magnitude of the outlier.

Four commonly used types of outliers (see Tsay, 1988) are employed to quantify the possible impact of a shock. They are additive outlier 
$(A O)$, innovational outlier $(I O)$, level shift (LS), and temporary change (TC). An additive outlier affects only the level of the given observation while an innovational outlier affects all observations beyond the given time through the memory of the underlying outlier-free process. A level shift is an event that affects a time series at a particular time point whose effect becomes permanent. A temporary change is an event having an initial impact and whose effect decreases exponentially according to a fixed dampening parameter, say, $\delta$. In practice the value of $\delta$ often lies between .6 and .8 (Liu and Hudak, 1994, p.76). We employ $d=.7$ in this article as recommended by Chen and Liu (1993).

Chen and Liu (1993) suggested a method for modelling time series with outliers. Their approach consists of a three-stage iterative procedure based on detection, estimation and adjustment. The outlierfree time series $X_{t}$ in equation 1 can be written as a linear combination of the current and past innovations, i.e.,

$$
X_{t}=\psi(L) e_{t},
$$

where

$$
\psi(L)=\theta(L) / \phi(L)=1-\psi_{1} L-\psi_{2} L^{2} \ldots
$$

The fitted residuals $\hat{e}_{t}=\left(Y_{t}-\hat{Y}_{t}\right)$, which may be contaminated with outliers, can be expressed by a dummy variable time series regression:

$$
\hat{e}_{t}=\omega D(i, t)+\varepsilon_{t}
$$

for $i=A O, I O, L C$ and $T C$, where $D(i, t)=0$ for all $i$ and $t<T, D(i, t)=$ 1 for all $i$ and $t=T$, and

$$
\begin{gathered}
D(A O, t)=-\psi_{t-T}, \\
D(I O, t)=0, \\
D(L S, t)=1-\sum_{j=1}^{t-T} \psi_{j},
\end{gathered}
$$




$$
D(T C, t)=\delta^{t-T}-\sum_{j=1}^{t-T-1} \delta^{t-T-j} \psi_{j}-\psi_{t-T}
$$

for $t>T$.

The maximum value of the standardized $t$-statistic for the slope (outlier effects) of the above regression in equation 4 can be used for detecting outliers, i.e.:

$$
T=\max _{1 \leq T \leq n} \max _{i \in\{A O, I O, L S, T C\}}\{\tau(i, T)\}
$$

where

$$
\tau(i, T)=\frac{\hat{\omega}(i, T)}{\sqrt{\operatorname{Var}[\hat{\omega}(i, t)]}},
$$

with

$$
\hat{\omega}=\frac{\sum_{t=T}^{n} \hat{e}_{t} D(i, t)}{\sum_{t=T}^{n}[D(i, t)]^{2}},
$$

and

$$
\operatorname{Var}[\hat{\omega}(i, t)]=\frac{\hat{\sigma}^{2}}{\sum_{t=T}^{n}[D(i, T)]^{2}} .
$$

For a given location, these standardized statistics follow a normal distribution approximately. An outlier is detected if $T$ is greater than a critical value $C$. We employ $C=3.5$ (as recommended by Liu and Hudak, 1994) in this paper. With the type and the location of an outlier, we can jointly re-estimate the model parameters and the outlier effects. After the estimation, one can adjust the outlier effects on the observations. The detection-estimation-adjustment cycle is repeated for the adjusted series until no new outliers are found. Finally, the model is re-estimated for the ARMA parameters and all outlier effects simultaneously. 


\section{Data and Empirical Results}

The following daily market indices are used to represent the market activities of the various regions in Greater China. The Hang Seng Index is chosen as a proxy of the stock market activities in Hong Kong. The index is composed of 33 constituent stocks selected from all sectors. It is market-value weighted and represents about $70 \%$ of total market capitalization. The Shanghai B-share index and Shenzhen B- share index, market-value weighted of all the listed B shares in the respective markets, are analyzed in this paper. The B-shares, being restricted to foreign investors who are mostly institutional investors, are less speculative than the A-shares and are more closely related to economic fundamentals (Brooks, 1995). The Taiwan Stock Exchange capitalization weighted stock index is the most widely quoted index of all the Taiwan Stock Exchange indices. This index covers all listed stocks excluding preferred stocks, full-delivery stocks and newly listed stocks which have been listed for less than one month. Our study covers the period from 5 October 1992 to 31 May 1999, giving a total of 1,736 daily time series observations. All indices are in local currencies. The data were obtained from Datastream.

Table 1 provides several descriptive statistics for market return time series, including mean, standard derivation, skewness and excess kurtosis. The coefficients of skewness are all significantly greater than zero except for the Taiwan market. Tests of significance of excess kurtosis in these markets indicate that Hong Kong and Mainland markets all have heavy "tail" return distributions.

The correlation matrix for market returns is:

\begin{tabular}{|c|c|c|c|c|}
\hline & Hong Kong & Shanghai & Shenzhen & Taiwan \\
\hline Honk Kong & 1 & & & \\
\hline Shanghai & .2297 & 1 & & \\
\hline Shenzhen & .158 & .5415 & 1 & \\
\hline Taiwan & .1867 & .0908 & .0546 & 1 \\
\hline
\end{tabular}


TABLE 1. Descriptive Statistics

\begin{tabular}{lrccccc}
\hline Market & Mean & Std. Dev. & Skewness & Kurtosis & Minimum & Maximum \\
\hline Hong Kong & .0004 & .0189 & .1379 & 6.98 & -.1473 & .1725 \\
Shanghai & -.0003 & .0209 & .4956 & 2.72 & -.1308 & .1218 \\
Shenzhen & -.0004 & .0210 & .2161 & 9.17 & -.1670 & .1380 \\
Taiwan & .0004 & .0155 & .0840 & 0.02 & -.0778 & .0852 \\
\hline
\end{tabular}

All correlation coefficients are positive. With 1,735 observations, the values over .048 would be significant at a $2.5 \%$ level, so four out of these six coefficients are highly significant, and the other two (correlations between Taiwan and the two Mainland markets) are not vastly significant.

We apply the procedure suggested by Chen and Liu (1993) to identify the large shocks in the four stock markets. The events associated with outliers are gathered from newspapers and magazines published in Hong Kong. The results are reported in the appendix. It is interesting to compare the nature of the events generating the outliers in the different markets. Most of the outliers in the Hong Kong market are generated by external events such as price movement in the major stock markets, particularly in the US stock market. This result is not surprising because the stock market in Hong Kong is the most developed and open among the Greater China economies.

The events related to the outliers in the Chinese markets are more difficult to identify. For a number of dates, there are no plausible events to explain the outliers. The event entries of these dates are left empty in the table of the appendix. Apparently many of the outliers are related to 'local factors' such as government policy announcement or execution. Similar observation is marked in the Taiwan market. Most of the outliers there seem to be generated by the government announcement of new policies. The only event that generated outliers in all the markets was the US market plunge on October 29, 1997.

It should be noted that an $A O$ affects only the observation on that day. On the other hand, both $I O$ and $T C$ shocks create a wave of impact which may last for a couple of days. An $L C$ outlier changes the 
TABLE 2. Distribution of the Types of the Detected Shocks

\begin{tabular}{|c|c|c|c|c|c|c|c|c|}
\hline \multirow{2}{*}{$\begin{array}{l}\text { Types of } \\
\text { Outliers }\end{array}$} & \multicolumn{2}{|c|}{ Hong Kong } & \multicolumn{2}{|c|}{ Shanghai } & \multicolumn{2}{|c|}{ Shenzhen } & \multicolumn{2}{|c|}{ Taiwan } \\
\hline & Number & $\%$ & Number & $\%$ & Number & $\%$ & Number & $\%$ \\
\hline$A O$ & 5 & 24 & 16 & 59 & 32 & 54 & 10 & 77 \\
\hline$I O$ & 12 & 57 & 6 & 22 & 14 & 24 & 0 & 0 \\
\hline$T C$ & 4 & 19 & 4 & 15 & 12 & 20 & 3 & 23 \\
\hline$L C$ & 0 & 0 & 1 & 4 & 1 & 2 & 0 & 0 \\
\hline Total & 21 & 100 & 27 & 100 & 59 & 100 & 13 & 100 \\
\hline
\end{tabular}

level of the series permanently. We perform a classification study of the types of the event shocks in the appendix. The distribution of the four types of outliers detected in each market is given in table 2. It is found that most $I O$ 's and $T C$ 's are generated by external events, such as extraordinary price or interest rate movements in the US market. The Hong Kong market is more sensitive to these types of shocks. The outliers detected in the Chinese markets and the Taiwan market are mostly $A O$ 's. These shocks are usually related to local events. Finally, $L C$ is rarely found in these markets. The $L C$ shock detected in May 1999 in the Shanghai market is due to the announcement of new regulations. The change in regulations creates a permanent shift of the level of the series in the Shanghai market.

The timing and size of the outliers are plotted as the time lines in figure 1 . The time lines clearly show distinctly different patterns across the economies. First, the Chinese stock markets contain significantly more outliers. This contrasts sharply with the Taiwan market, where only sporadic outliers are identified. The Hong Kong market has apparently more outliers identified than Taiwan, despite the fact that the former possesses a more mature stock market. It may be due to the fact that the Taiwan government has closely monitored and intervened in the market activities. Moreover, a closer inspection reveals that there are clusters of outliers in the Hong Kong market in the periods from October 1997 through March 1998 as well as June 1998 through January 1999. This is an indication that Hong Kong has been harder hit by the episode of the 1997 Asian financial crisis, whereas Taiwan was basically immunised. Finally, it is found that the number of positive shocks and the number of negative shocks within 

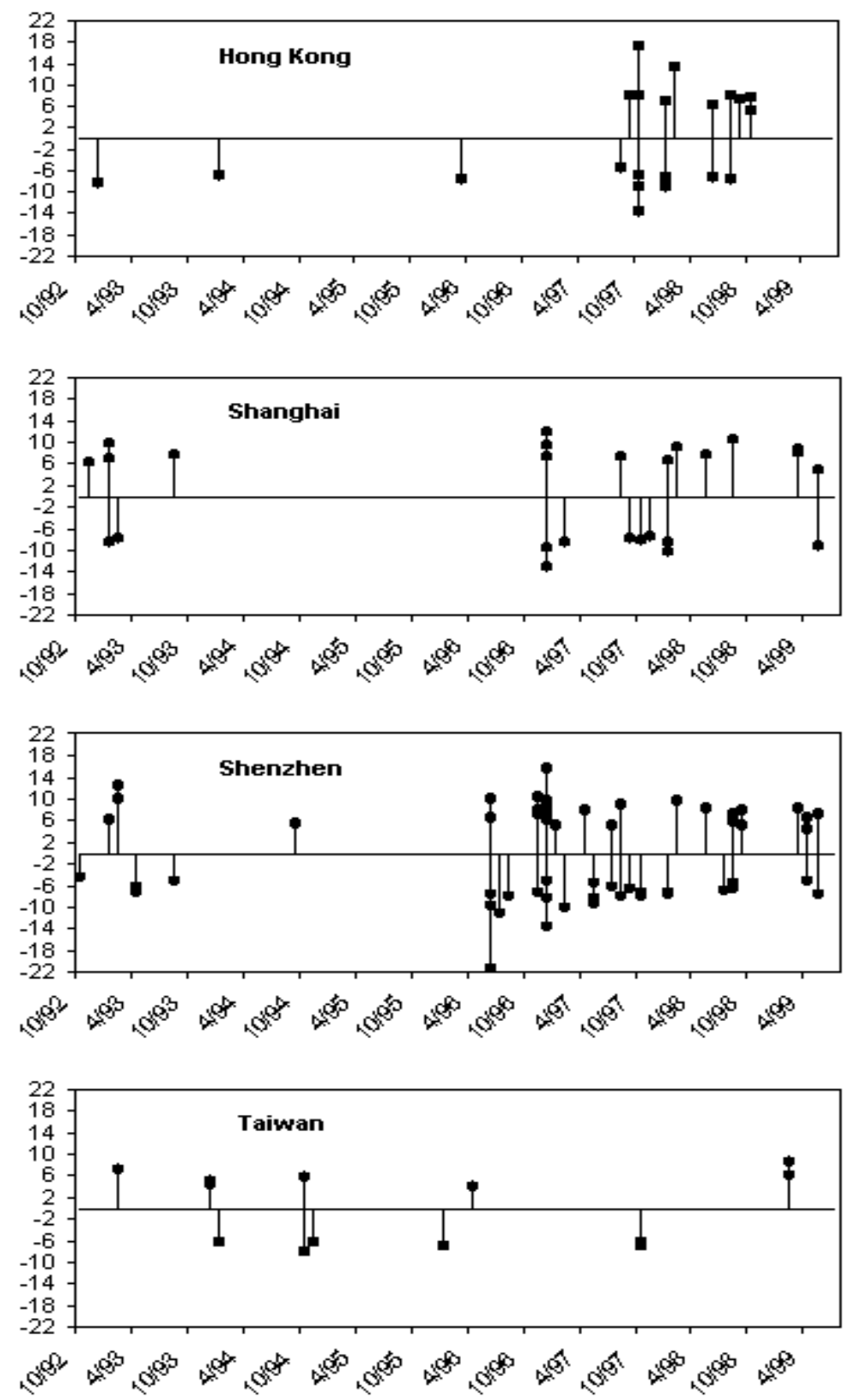

FIGURE 1.- Sizes and Timings of the Detected Shocks 
TABLE 3. Sample Variances for Returns in Different Markets

\begin{tabular}{lcllc}
\hline & Hong Kong & Shanghai & Shenzhen & Taiwan \\
\hline Before Outlier Adjustments & $3.5721 \%^{2}$ & $4.3823 \%^{2}$ & $4.4108 \% \%^{2}$ & $2.3872 \%^{2}$ \\
After Outlier Adjustments & $2.5209 \%^{2}$ & $3.0560 \%$ & $1.7012 \%$ & $2.0454 \%^{2}$ \\
Percentage of Volatility & $29.0 \%$ & $30.0 \%$ & $61.0 \%$ & $14.0 \%$ \\
Reduction due to Outliers & & & & \\
\hline
\end{tabular}

each market are roughly the same.

To show the degree of significance of outliers, we compute the sample variance of the four markets with the outliers suppressed. The results are reported in table 3 . The outliers are most significant in Shenzhen, accounting for $61 \%$ of the sample variance, whereas outliers in Taiwan market contribute to only $14 \%$ of the market volatility. These results indicate that the Chinese markets are more susceptible to large shocks.

\section{Conclusion}

Using a modified outlier identification procedure by Chen and Liu (1993), we analyse the large shocks in the stock markets of Hong Kong, Shanghai, Shenzhen and Taiwan. We find that large shocks are found in all the markets that we investigate. Several patterns emerge. First, with the exception of Hong Kong, the outliers seem to be driven by local events. In particular, the outlier pattern of the Taiwan market is distinctively different. Second, more outliers are detected in the Chinese stock markets than in the other markets. The fact that the Chinese markets are more susceptible to large shocks could have strong implication in the risk diversification of investment portfolio. Lastly, most of the outliers identified in the Hong Kong market appear in the periods of the 1997 Asian financial crisis and after the Government's market intervention in August 1998. It is interesting to observe that the government market intervention in August 1998 seems to make the market more susceptible to large shocks. 


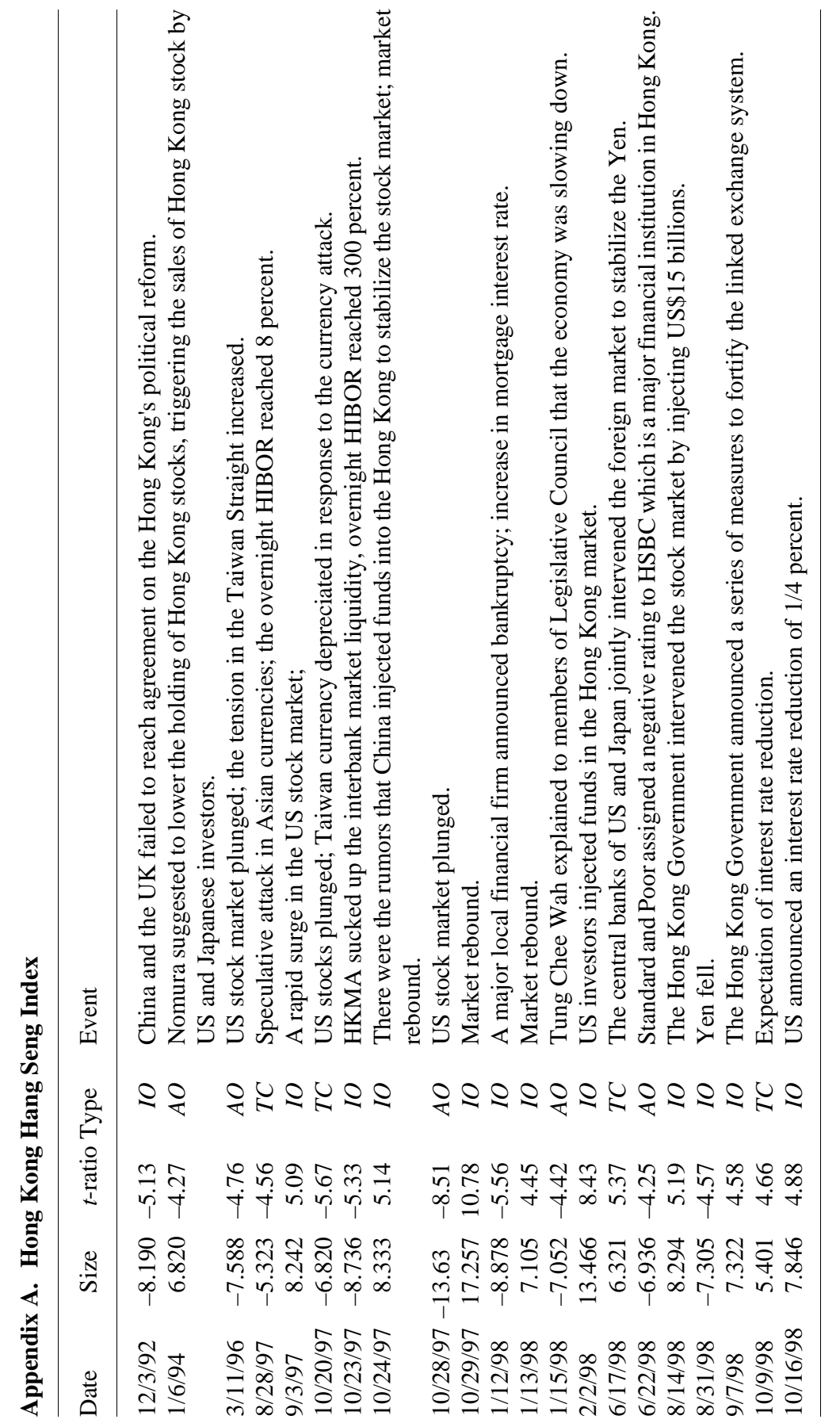




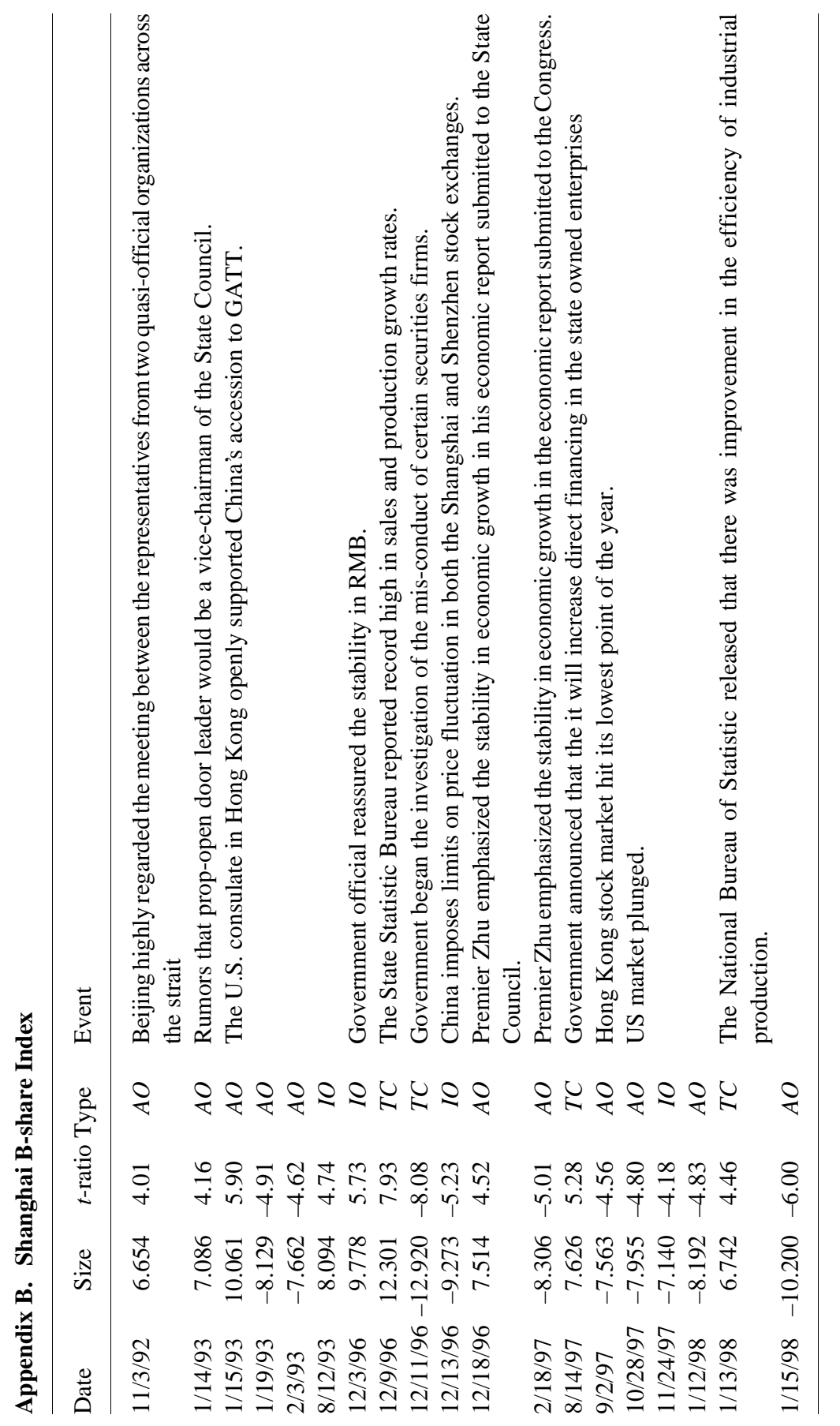




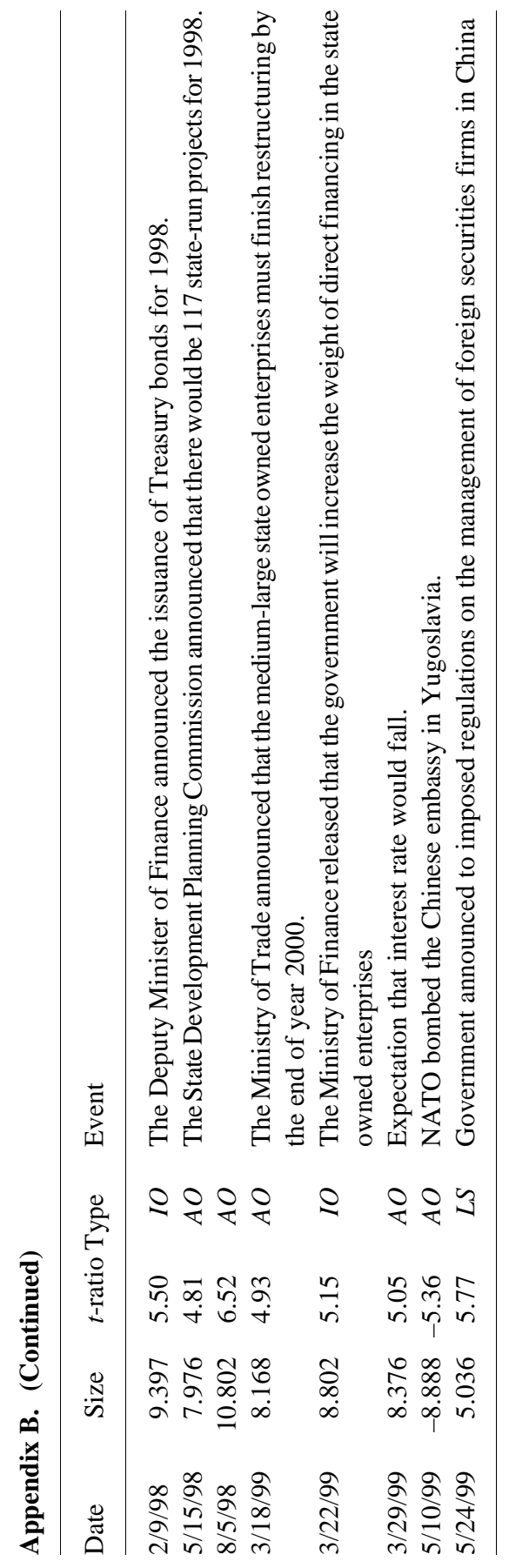




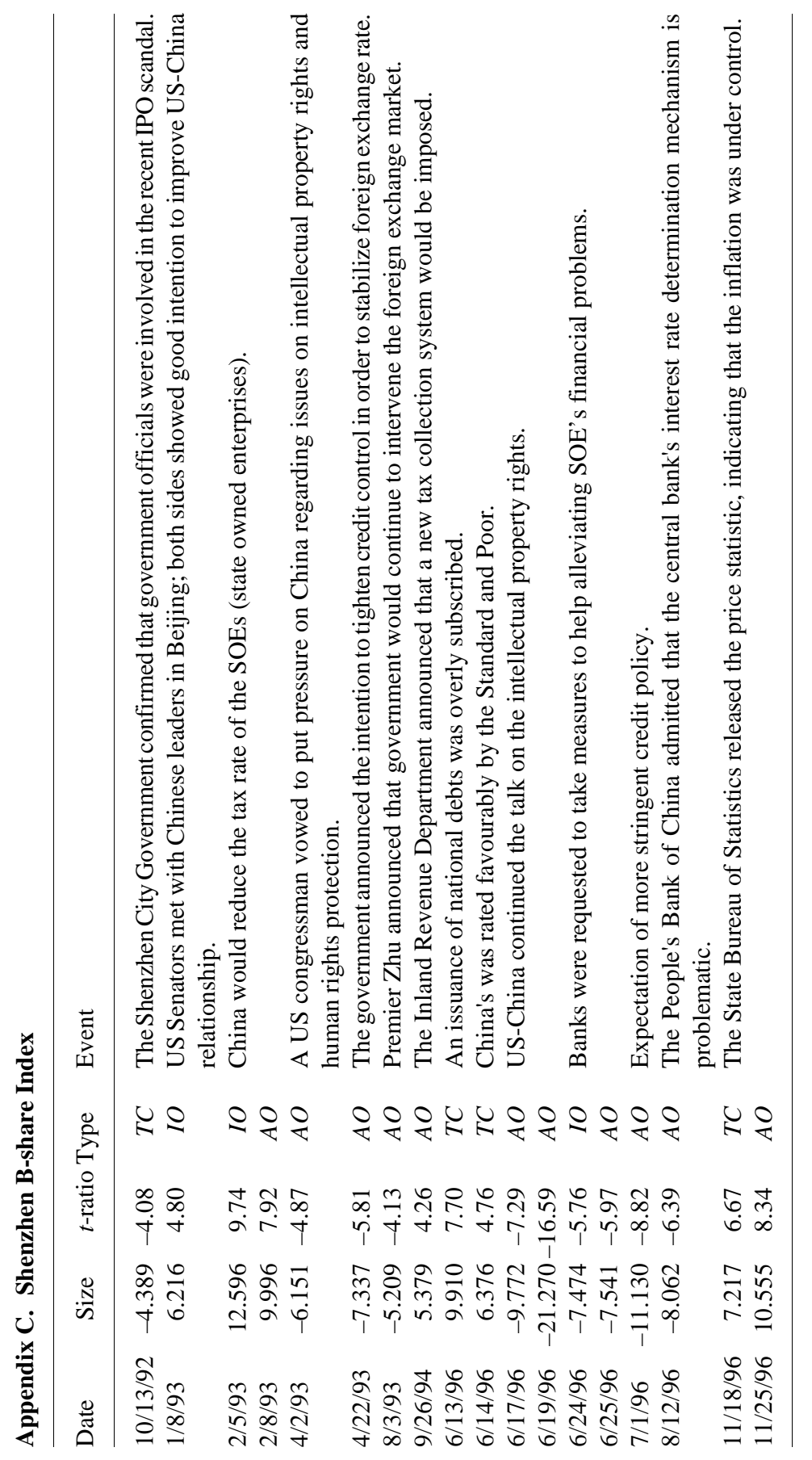




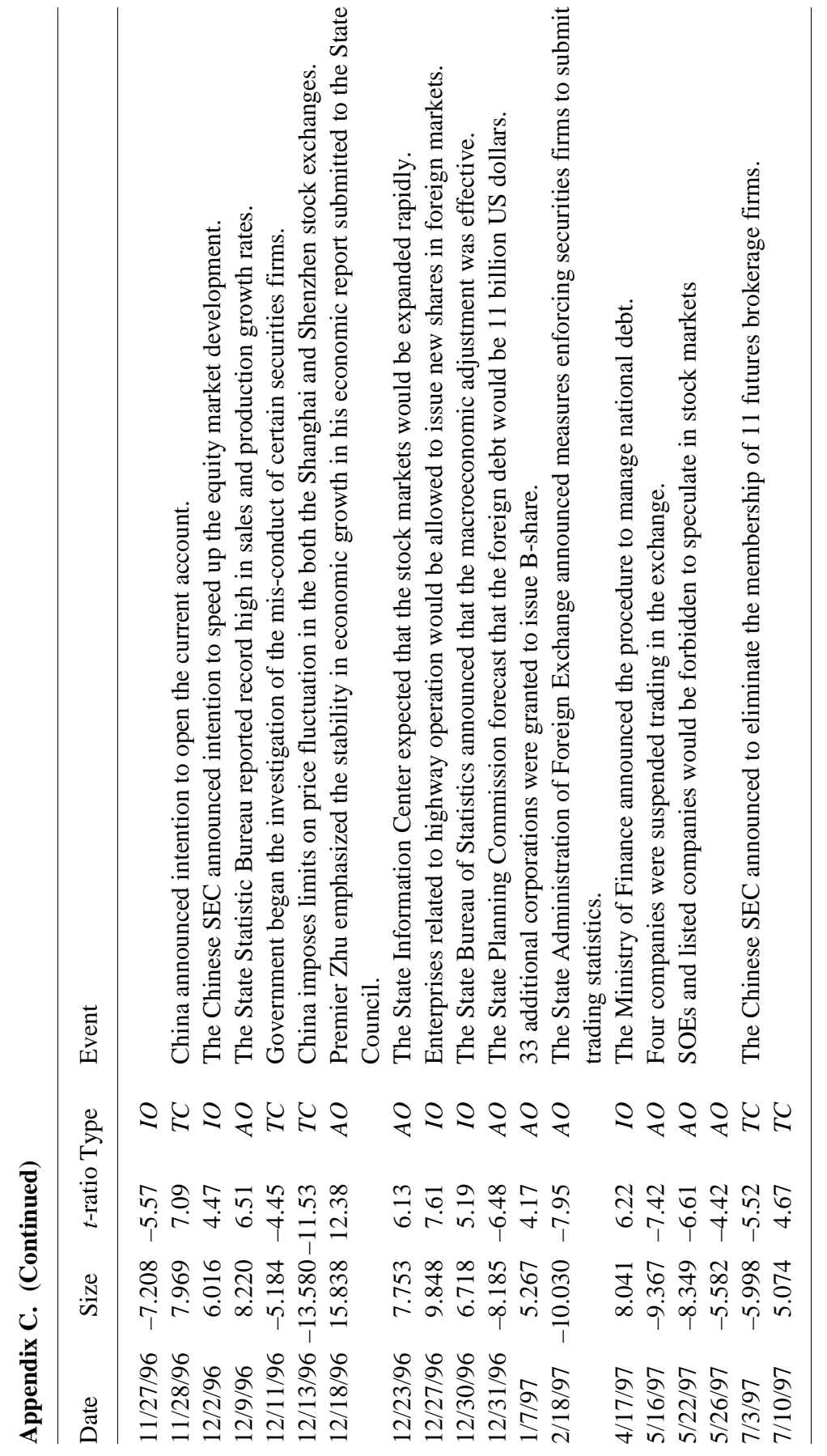




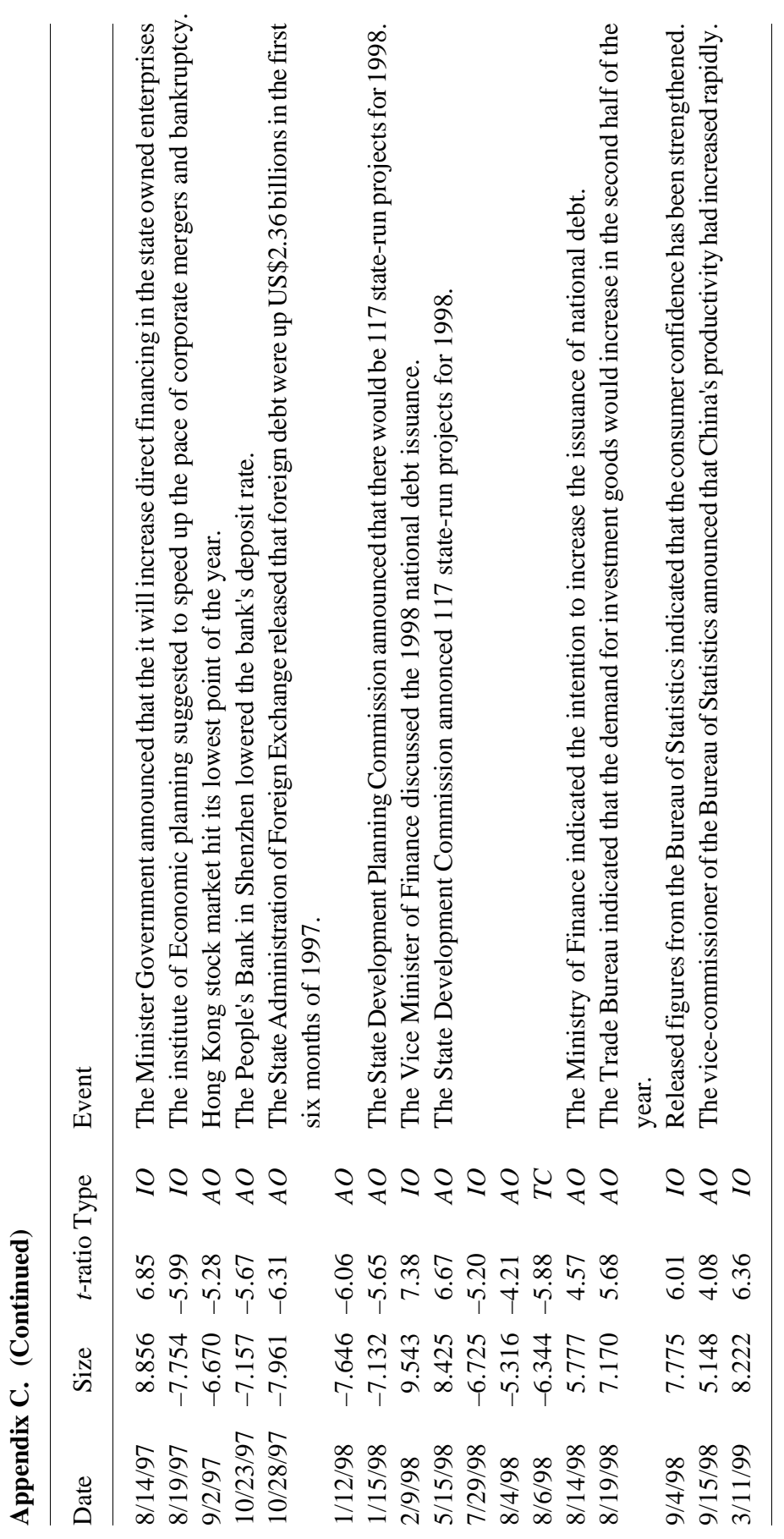




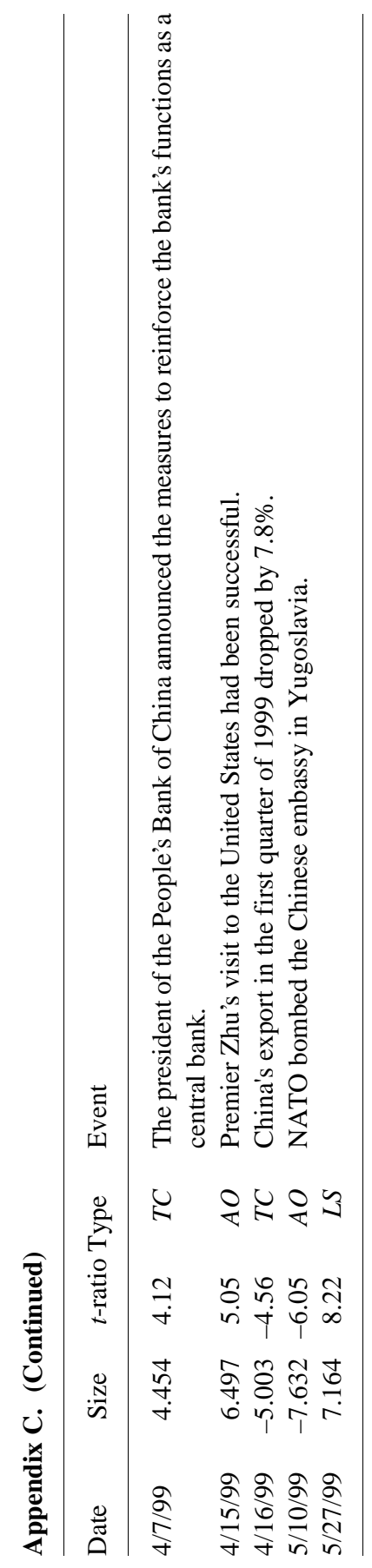




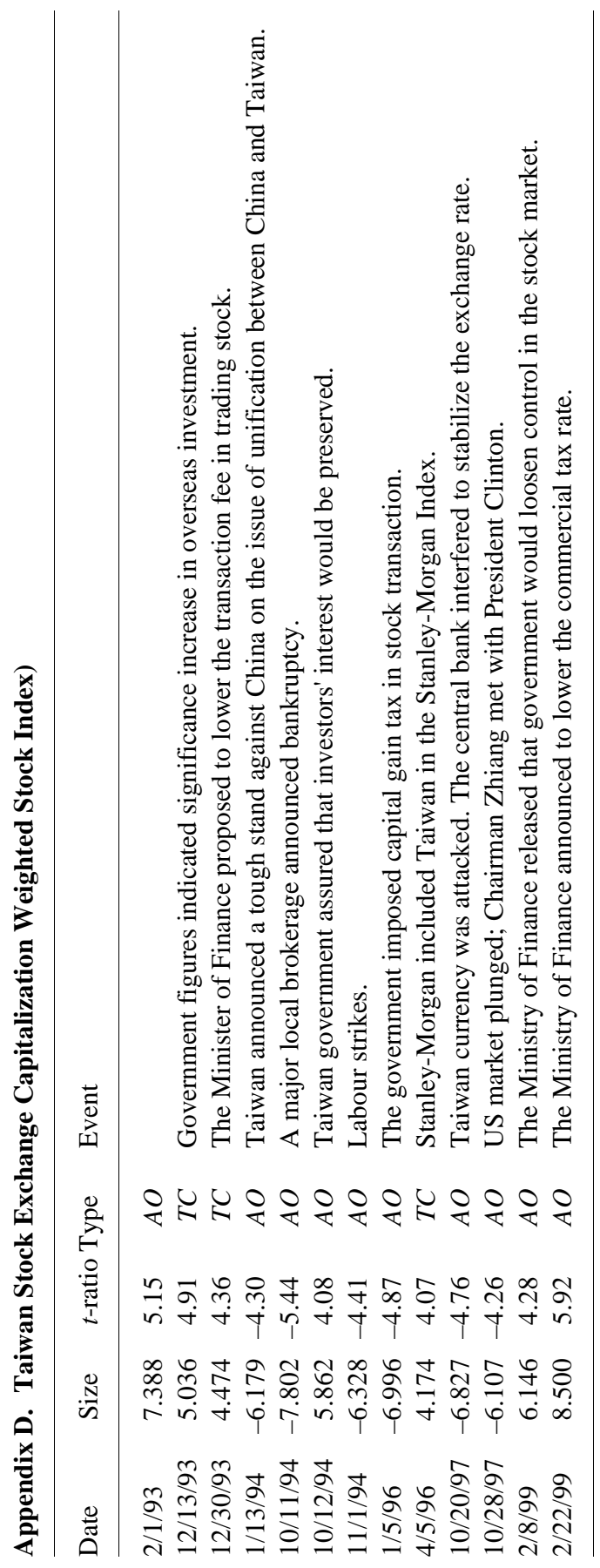




\section{References}

Ash, R., and Kueh, Y. 1993. Economics integration within Greater China: Trade and investment flows between China, Hong Kong and Taiwan. China Quarterly 136: 711-45.

Balke, N.S., and Fomby, T.B. 1994. Large shocks, small shocks, and economic fluctuations: Outliers in macroeconomic time series. Journal of Applied Econometrics 9 (2): 181-200.

Brooks, J. 1995. China's stock markets. In K.Y. Cao (ed.), The Changing Capital Markets of East Asia. London: Rouledge.

Chan, W. S.; Lo, W. C.; and Cheung, S. H. 1999. Return transmission among stock markets of Greater China. Mathematics and Computers in Simulation 48: 511-18.

Chen, C., and Liu, L.M. 1993. Joint estimation of model parameters and outlier effects in time series. Journal of the American Statistical Association 88: 284-97.

Chou R. Y.; Lin J. L; and Wu C. S. 1999. Modeling the Taiwan stock market and international linkages. Pacific Economic Review 4(3): 305-20.

Jones, R.; King, R.; and Klein, M. 1993. Economic integration between Taiwan, Hong Kong and the coastal provinces of China. OECD Economics Studies 20: 115-44.

Lee, Y. T.; Lin J. C.; and Liu Y. J. 1999. Trading patterns of big versus small players in an emerging market: An empirical analysis. Journal of Banking and Finance 23(5): 701-25.

Levine, R., and Zervos, S. 1998. Capital control liberalization and stock market development. World Development 26(7): 1169-83.

Liu, L.M., and Hudak, G.B. 1994. Forecasting and time series analysis using the SCA system. Chicago: Scientific Computing Associates.

Naughten, B. 1997. The China circle: Economics and electronics in the PRC, Taiwan, and Hong Kong. New York: Brookings Institute Press.

Ragunathan, V. 1999. Financial deregulation and integration: An Australian perspective. Journal of Economics and Business 51(6): 505-14.

$\mathrm{Su}$, D. 1999. Ownership restriction and stock price: Evidence from Chinese markets. Financial Review 34(2): 37-56.

$\mathrm{Su}$, D., and Fleisher, B. M. 1999. Why does return volatility differ in Chinese stock markets? Pacific Basin Finance Journal 7(5): 557-86.

Song, H.; Liu, X.; and Romilly, P. 1998. Stock returns and volatility: An empirical study of Chinese stock markets. International Review of Applied Economics 12(1): 129-39.

Sung, Y. W. 1992. Non-institutional Economic Integration Via Cultural Affinity: The case of Mainland China, Taiwan and Hong Kong. Hong Kong Institute of Asia-Pacific Studies, The Chinese University of Hong Kong. 
Tsay, R. S. 1988. Outliers, level shifts, and variance changes. Journal of Forecasting 7:1-20.

$\mathrm{Xu}$., and Wang, Y. 1999. Ownership structure and corporate governance in Chinese stock companies. China Economic Review 10(1): 75-98. 